\title{
Rapid Degradation of Atrazine by Hydroxyl Radical \\ Induced from Montmorillonite Templated Subnano-sized Zero-Valent Copper
}

\author{
Ran Hong ${ }^{1}$, Zupei Guo ${ }^{1}$, Juan $\mathrm{Gao}^{2}$, Cheng Gu* \\ ${ }^{1}$ State Key Laboratory of Pollution Control and Resource Reuse, School of the \\ Environment, Nanjing University, Nanjing 210023, P.R. China \\ ${ }^{2}$ Key Laboratory of Soil Environment and Pollution Remediation, Institute of \\ Soil Science, Chinese Academy of Sciences, Nanjing, Jiangsu 210008, P. R. China
}

*To whom correspondence should be addressed

Cheng Gu

Professor

School of the Environment

Nanjing University

Nanjing, Jiangsu, 210023

P. R. China

Phone/Fax: +86-25-89680636 
E-mail: chenggu@nju.edu.cn 


\section{Abstract}

In this study, subnano-sized zero-valent copper (ZVC) was synthesized using montmorillonite clay mineral as the template. The discrete distribution of surface charge on montmorillonite effectively separates the formed ZVC particles and inhibits their aggregation. X-ray diffraction result indicates that the size of ZVC particles on montmorillonite is $\sim 6 \AA$, which is much smaller than nano-ZVC prepared by conventional method. The montmorillonite templated ZVC (ZVCMMT) shows superior reactivity as indicated by the degradation of atrazine, over $90 \%$ atrazine (15 $\mu \mathrm{M})$ could be degraded in a few min. Hydroxyl radical is confirmed as the reactive species, which is produced from the activation of oxygen by ZVC. It was also shown that the degradation process is strongly dependent on the hydration status of synthesized ZVCMMT. The freeze dried ZVCMMT exhibits higher reactivity compared to freshly prepared ZVCMMT, which can be explained by the higher adsorption of atrazine and oxygen residue on freeze dried ZVCMMT surface. In addition, the toxicity of atrazine is significantly decreased after the reaction with ZVCMMT, indicating that ZVCMMT could be used as a promising material for rapid remediation of persistent organic contaminants.

Keywords: zero-valent copper; molecular oxygen activation; in-situ $\mathrm{H}_{2} \mathrm{O}_{2}$ generation; montmorillonite; atrazine 


\section{Introduction}

Due to the strong reductive activity, zero-valent metals (ZVMs) have been extensively studied and widely used for environmental remediation of various heavy metals and organic contaminants (Ponder et al., 2000; Dries et al., 2005; Jacqueline et al., 2005). It has been shown that ZVMs can effectively reduce chromate (VI) (Liu et al., 2008), nitro-aromatic compounds (Gu et al., 2010), and chlorinated organic chemicals (Pearson et al., 2005) under anaerobic conditions. However, recent studies reveal that ZVMs could also induce Fenton-like reactions to eliminate organic pollutants by activing the molecular oxygen (Joo et al., 2004; Englehardt et al., 2007; Katsoyiannis et al., 2008; Keenan and Sedlak, 2008a; b). For instance, in the case of zero-valent iron (ZVI), the reaction is initiated by a two-electron transfer from ZVI to the oxygen adsorbed on its surface and forms a reduced oxygen anion $\left(\mathrm{O}_{2}{ }^{2-}\right)$, which could subsequently protonate and finally generate hydrogen peroxide $\left(\mathrm{H}_{2} \mathrm{O}_{2}\right)$ in the presence of free protons (Keenan and Sedlak, 2008a). It was also reported that $\mathrm{H}_{2} \mathrm{O}_{2}$ could be produced through a one-electron transfer process by reaction between ferrous iron and oxygen (Huang et al., 2002; Kim et al., 2015). The formed $\mathrm{H}_{2} \mathrm{O}_{2}$ can be further decomposed into hydroxyl radical $(\cdot \mathrm{OH})$ catalyzed by $\mathrm{Fe}^{2+}$, and $\cdot \mathrm{OH}$ is considered as one of the most reactive species to oxidize many organic contaminants (Buxton et al., 1988).

Among the ZVMs, ZVI is most studied. Due to the strong reduction potential, 
especially under acidic conditions, ZVI can be consumed by free protons to form $\mathrm{H}_{2}$ directly (Wang et al., 2014), which might limit the usage of ZVI at low pH. However, as protons are necessary to dismutate $\cdot \mathrm{O}_{2}{ }^{-}$, low $\mathrm{pH}$ would be essential for the production of $\mathrm{H}_{2} \mathrm{O}_{2}$ (Keenan and Sedlak, 2008a). Therefore, it is desirable to find other ZVMs to overcome the drawbacks of ZVI. Copper has a standard reduction potential of $0.34 \mathrm{~V}\left(\mathrm{Cu}^{2+} / \mathrm{Cu}\right)$ (Gang et al., 2014), which would prevent the reaction with protons via displacement reaction to produce $\mathrm{H}_{2}$ gas. Thus this renders zero-valent copper (ZVC) as an alternative for ZVI.

Currently, only a few researches have been conducted to investigate the reactivity of ZVC. A prior study showed that ZVC could effectively degrade azo dyes by activation of molecular oxygen to produce $\mathrm{Cu}^{+}$and $\cdot \mathrm{OH}$, leading to the cleavage of $\mathrm{N}=\mathrm{N}$ bonds of the azo dyes through a Sandmeyer reaction under neutral $\mathrm{pH}$ and aerobic conditions (Dong et al., 2014). The results from Gang and his co-workers (Gang et al., 2014) indicated that ZVC exhibited higher persistent oxidation capacity compared to ZVI, zero-valent aluminum and zero-valent zinc as indicated by the oxidative degradation of diethyl phthalate.

Due to the high surface area and reactivity, nano-sized ZVC (nZVC) was synthesized by various methods. For example, nZVC can be formed by addition of $\mathrm{NaBH}_{4}$ to reduce $\mathrm{Cu}^{2+}$ to $\mathrm{Cu}^{0}$, and the average diameter is about $50 \mathrm{~nm}$ (Huang et al., 2012). A solvothermal method was also developed to synthesize nZVC with the 
diameter of $\sim 30 \mathrm{~nm}$ (Dong et al., 2014). It is well known that nanoparticles tend to agglomerate, which diminishes their reactivity. Hence, different strategies have been employed to stabilize the formed nanoparticles. Stabilizers such as carboxylic acids and polyvinyl alcohol (Khanna et al., 2007), oleylamine (Dadgostar et al., 2010), and poly amidoamine dendrimers (Balogh and Tomalia, 1998) have been used to disperse copper nanoparticles. Whereas, these stabilizers are all organic chemicals, which might interfere with the reactive oxygen species (ROS) generated from the activation of oxygen by ZVC.

Montmorillonite is a common clay mineral widely distributed in soils, subsoils and sediments (Gu et al., 2008). As a natural nanomaterial, the size of elementary platelet of montmorillonite is a few tens to hundreds of nanometers wide and 1-1.8 nanometers thick (Pinnavaia, 1983; Laszlo, 1987). Our previous studies showed that montmorillonite could be used as a template to synthesize subnano-sized ZVI ( $\mathrm{Gu}$ et al., 2010; Zhang et al., 2015). With the unique structure of montmorillonite, ZVI was formed in the constrained interlayer region of montmorillonite with average size of $0.5 \mathrm{~nm}$. The montmorillonite template ZVI showed higher reactivity and efficiency compared to other forms of ZVIs (Gu et al., 2010). Therefore, it is expected that highly reactive nZVC could also be formed with montmorillonite as the supporting matrix.

Atrazine was used worldwide as the herbicide since 1958 and has been banned in 
the European Union in 2004 due to its highly persistent nature in the environment. It has been reported that the concentration of atrazine could reach $0.068 \mu \mathrm{g} \mathrm{L}^{-1}$ in groundwater even after 21 years since its last application (Vonberg et al., 2014). Atrazine can cause chronic prostatitis (Stanko et al., 2010) and mammary gland development problems in Long-Evans rats after a prenatal exposure (Enoch et al., 2007). It also can cause algae death after an acute exposure (Ralston-Hooper et al., 2009). Recently, numerous methods have been developed to remove atrazine through oxidation (Guan et al., 2013; Hu and Cheng, 2014), reduction (Stephen et al., 1998) and biological degradation (Ghosh and Philip, 2004).

In this study, a new method to synthesize nZVC was developed using natural montmorillonite as the support and the degradation process of atrazine by this montmorillonite templated nZVC (ZVCMMT) through a Fenton-like reaction was investigated without addition of $\mathrm{H}_{2} \mathrm{O}_{2}$. The results clearly demonstrate that the isolated distribution of exchangeable $\mathrm{Cu}^{2+}$ effectively separates the nZVC nanoparticles and prevents their aggregation upon the reduction by $\mathrm{NaBH}_{4}$. With the smaller particle size (6 ̊), ZVCMMT exhibits exceptional reactivity for the decomposition of atrazine under acidic conditions, as the initial degradation rate increases 27 and 13 times compared to commercial available ZVC $(\sim 20 \mu \mathrm{m})$ and nZVC ( 25 nm) prepared by conventional method, respectively. Our results also indicated that the degradation process is strongly affected by the hydration status of 
ZVCMMT. Freeze dried ZVCMMT showed higher reactivity than the freshly prepared, which may be explained by the higher adsorption of atrazine and residual oxygen on the surface of dried clay minerals.

\section{Materials and Methods}

\subsection{Chemicals}

Atrazine (99.1\%) and its metabolites (atrazine-desethyl (DEA), 99.5\%; atrazine-desisopropyl (DIA), 97.5\%; atrazine-desethyl-desisopropyl (DEDIA), 96.3\%), and atrazine standard solution (101 $\mathrm{ng} \mu \mathrm{L}^{-1}$, dissolved in methanol) were obtained from Fluka (Ronkonkoma, NY, USA). Xanthine, xanthine oxidase, sodium borohydride, copper chloride dihydrate, zero-valent copper powder (spheroidal) with the average diameter size of $20 \mu \mathrm{m}$ and 5,5-dimethy-1-pyrroline $N$-oxide (DMPO) were all purchased from Sigma-Aldrich. Methanol and acetonitrile were of HPLC grade and from Merk (Darmstadt, Germany). All the chemicals were used as received without any further purification.

\subsection{Preparation of ZVCMMTs and nZVC}

Montmorillonite clay mineral used in this study was obtained from Fenghong Chemical Co. (Zhejiang Province, China) with the measured cation exchange capacity (CEC) of $77 \mathrm{cmol} \mathrm{kg}^{-1}$. The preparation of ZVCMMT followed the method of Gu and his co-workers (Gu et al., 2010). Briefly, $\mathrm{Na}^{+}$-montmorillonite was initially exchanged with cupric ion $\left(\mathrm{Cu}^{2+}\right)$ by simply saturating the clay mineral using $0.1 \mathrm{M} \mathrm{CuCl}_{2}$ 
solution. Copper content in clay mineral was determined by a flame atomic absorption spectrometry (Thermo fisher, M6, USA) after digestion with a mixture of hydrofluoric and hydrochloric acid. Then, the $\mathrm{pH}$ of the $\mathrm{Cu}^{2+}$-montmorillonite slurry was adjusted to $\sim 2$ using $1 \mathrm{M} \mathrm{HClO}_{4}$ before addition of $\mathrm{NaBH}_{4}$ with the molar ratio of $\mathrm{NaBH}_{4} / \mathrm{Cu}^{2+}$ $=30$. Finally, the clay suspension was washed with oxygen free water to remove the excess of $\mathrm{NaBH}_{4}$. For each experiment, ZVCMMT was freshly prepared. In addition, a portion of ZVCMMT was freeze dried to investigate the effect of hydration status on the degradation of atrazine, which was then stored in a desiccator with nitrogen gas atmosphere. Montmorillonite templated zero-valent iron (ZVIMMT) was also prepared following the same procedure as ZVCMMT.

Nano-sized ZVC was synthesized with the modified method from Huang and his co-workers (Huang et al., 2011). $\mathrm{CuCl}_{2}(0.05 \mathrm{M})$ and $\mathrm{NaBH}_{4}(0.15 \mathrm{M})$ solutions were mixed with the volume ratio of 1:1, and then washed by oxygen free water to removal excessive $\mathrm{NaBH}_{4}$ until the $\mathrm{pH}$ of the supernatant was in the range between 6 and 7 after centrifugation. The synthesized nZVC was then freeze dried and stored under anaerobic condition.

\subsection{Characterization of ZVCMMTs}

The powder diffraction pattern of the freeze dried ZVCMMT was collected between $2^{\circ}$ to $14^{\circ}$ at a scanning rate of $1^{\circ} \min ^{-1}$ by X-ray diffractometer (XRD) (X'TRA, ARL, Switzerland) with graphite monochromated $\mathrm{CuK} \alpha$ radiation $(\lambda=1.5406$ 
$\AA$ ), operating at $40 \mathrm{kV}$ and $40 \mathrm{~mA}$. To confirm the reduction of $\mathrm{Cu}^{2+}$ to $\mathrm{Cu}^{0}$, the freeze dried ZVCMMT sample was analyzed by X-ray photoelectron spectroscopy (XPS) (PHI 5000 VersaProbe, UlVAC-PHI, Japan) with a monochromatic AlK $\alpha$ source. Transmission electron microscope (TEM) (Tecnai $\mathrm{G}^{2} \mathrm{~F} 20$ 200-kV field emission microscope) was used to obtain the image of synthesized material and to measure the particle size. X-ray energy dispersive spectroscopy (EDS) was also equipped with TEM and employed to identify the element composition and distribution on ZVCMMT and nZVC before and after the reactions. BET surface areas of commercially available ZVC, nZVC, ZVCMMT and $\mathrm{Cu}^{2+}$-montmorillonite were evaluated using a surface area and porosity analyzer (Micromeritics, ASAP 2020, USA).

\subsection{Degradation of atrazine by ZVCMMTs, ZVIMMT, nZVC and commercial}

\section{available ZVC}

The degradation experiment was conducted at room temperature $\left(23^{\circ} \mathrm{C}\right)$ in a 250 $\mathrm{mL}$ conical flask with a magnetic stir at $600 \mathrm{rpm}$ to ensure sufficient oxygen supply. The initial concentrations for atrazine and ZVCMMTs were $15 \mu \mathrm{M}$ and $0.5 \mathrm{~g} \mathrm{~L}^{-1}$, respectively. In comparison studies, the concentrations for nZVC, commercially available ZVC and ZVIMMT were also at $0.5 \mathrm{~g} \mathrm{~L}^{-1}$. No organic solvent was used to avoid any possible quenching effect for radicals produced during the reaction. The initial $\mathrm{pH}$ of the solution was adjusted to 3.0, 4.5 and 6.0 by addition of $1 \mathrm{M} \mathrm{HClO}_{4}$ or 
$1 \mathrm{M} \mathrm{NaOH}$. The $\mathrm{pH}$ of the system before and after reaction was monitored with a calibrated $\mathrm{pH}$ meter (Thermo Scientific, ORION 5 STAR, USA). At predetermined time intervals, aliquot of $0.5 \mathrm{~mL}$ reaction solution was withdrawn and transferred to a glass tube containing $1 \mathrm{~mL}$ methanol, then vortexed for $15 \mathrm{~min}$. Methanol was used as both quenching and extraction agent. After the extraction, sample was filtered through a $0.22 \mu \mathrm{m}$ polytetrafluoroethylene syringe filter and stored at $4{ }^{\circ} \mathrm{C}$, then analyzed within $24 \mathrm{~h}$. Our preliminary experiments showed that the recovery for atrazine was higher than 95\%. Similar experiment was also conducted inside the anaerobic chamber.

Atrazine concentration was analyzed by a HPLC system (Waters Alliance 2695, Milford, MA, USA) with a C18 column (5 $\mu \mathrm{m}, 4.6 \times 250 \mathrm{~mm}$, Waters SunFire) monitored at the wavelength of $220 \mathrm{~nm}$ by a photodiode array detector (Waters Alliance 2998, Milford, MA, USA) with the injection volume of $25 \mu \mathrm{L}$. The reaction products were identified by comparing the retention times of the intermediates with the standards we obtained. The same HPLC system was used, and the mobile phase consisted of acetonitrile-water gradient elution with a constant flow rate of $1 \mathrm{~mL} \mathrm{~min}{ }^{-1}$. The gradient started with $5 \%$ acetonitrile and $95 \%$ water, then linearly increased to $35 \%$ acetonitrile within $50 \mathrm{~min}$, finally returned to the initial condition in $2 \mathrm{~min}$ and held for another $8 \mathrm{~min}$ for equilibration. The reaction products were also analyzed by GC-MS (Thermo Scientific, trace1030 ISQ, USA) after the sample was concentrated 
with solid phase extraction (SPE) method. Details of GC-MS and SPE methods were described in text S1 and text S2.

Concentration of $\mathrm{H}_{2} \mathrm{O}_{2}$ produced in the reaction system was determined by the photometric method (Gang et al., 2014), in which N,N-diethyl-p-phenylenediamine was oxidized by a peroxidase catalyzed reaction. To determine the active ROS for oxidation of atrazine, methanol was utilized as a probe molecule to quench $\cdot \mathrm{OH}$ due to its fast reaction with $\cdot \mathrm{OH}\left(9.8 \times 10^{8} \mathrm{~L} \mathrm{~mol}^{-1} \mathrm{~s}^{-1}\right)$ (Buxton et al., 1988). To test the possibility for the reaction of atrazine with $\cdot \mathrm{O}_{2}^{-}$, xanthine $(1 \mathrm{mM})$ and xanthine oxidase $\left(0.2\right.$ unit $\left.\mathrm{mL}^{-1}\right)$ were used to generate $\cdot \mathrm{O}_{2}^{-}$(Dong et al., 2014).

The radicals produced in the system were monitored by electron paramagnetic resonance (EPR) spectrometer (EMX-10/12, Bruker, Germany) at room temperature. DMPO was used as the effective radical scavenger. For the EPR measurement, clay and DMPO concentrations were $5 \mathrm{~g} \mathrm{~L}^{-1}$ and $40 \mathrm{mM}$, respectively. The instrumental parameters for EPR analysis were: microwave frequency and power at $9.85 \mathrm{GHz}$ and $20 \mathrm{~mW}$, modulation frequency and modulation amplitude at $100 \mathrm{kHz}$ and $1 \mathrm{G}$, receiver gain at $1.0 \times 10^{3}$, sweep width at $200 \mathrm{G}$ and center field at $3510 \mathrm{G}$.

The concentration of copper in solution after reaction was measured with a flame atomic absorption spectrometry (Thermo Fisher, M6, USA) after filtration. The generation of $\mathrm{H}_{2}$ during the reaction in the ZVIMMT and ZVCMMT systems was evaluated in a $40 \mathrm{~mL}$ gas-sealed bottle with $10 \mathrm{~mL}$ headspace volume. The amount of 
hydrogen gas in the headspace was measured using a gas chromatography (GC, BeiFen3420A, China) coupled with a thermal conductivity detector.

\subsection{Effect of hydration status of ZVCMMT on the degradation of atrazine}

To investigate the effect of hydration status of synthesized ZVCMMT on the degradation process, experiments for both freshly prepared and freeze dried ZVCMMT were conducted following the same procedure as described above. During the reduction of $\mathrm{Cu}^{2+}$-montmorillonite by $\mathrm{NaBH}_{4}$, the negative charges on clay mineral originally balanced by $\mathrm{Cu}^{2+}$ ion would be compensated by $\mathrm{Na}^{+}$( $\mathrm{Gu}$ et al., 2010). Therefore, the adsorption of atrazine on freshly prepared and freeze dried $\mathrm{Na}^{+}$-montmorillonite was also studied. The concentrations for $\mathrm{Na}^{+}$-montmorillonite and atrazine used in adsorption experiment were $12.5 \mathrm{mg} \mathrm{mL}^{-1}$ and in the range between 1.42 and $44.31 \mu \mathrm{M}$, respectively.

\subsection{Computational methods}

Molecular orbital calculation of atrazine was carried out using B3LYP/6-311G** method with Gaussian 09W program (Frisch et al.). The frontier electron densities (FEDs) of the highest occupied molecular orbital (HOMO) and the lowest unoccupied molecular orbital (LUMO) were determined from Gaussian output files. The values of $2 \mathrm{FED}^{2}{ }_{\text {номо }}$ and $\left(\mathrm{FED}_{\text {номо }}^{2}+\mathrm{FED}_{\text {LUMO }}^{2}\right)$ were used to predict the reaction sites of atrazine.

\subsection{Toxicity assay}


The change of acute toxicity before and after reaction with ZVCMMT was assessed by luminescent bacteria test (Vibrio fischeri) according to the standard method of ISO11348-3-2007. Before the test, $\mathrm{pH}$ was adjusted to 7.0 with $\mathrm{HClO}_{4}(1$ M) or $\mathrm{NaOH}(1 \mathrm{M})$ and the residual particles were removed through centrifugation.

\section{Results and discussion}

\subsection{Characterization of ZVCMMT}

As shown in table S1, negligible amount of copper was detected in reference montmorillonite $\left(\mathrm{Na}^{+}\right.$-montmorillonite), indicating that almost no copper is present in clay crystal structure. The measured copper content in $\mathrm{Cu}^{2+}$-montmorillonite was $\sim 4.3 \%$ (w/w) after clay mineral was saturated by $\mathrm{Cu}^{2+}$ ion (Tab. S1). It was worth noting that based on the CEC of montmorillonite $\left(77 \mathrm{cmol} \mathrm{kg}^{-1}\right)$, the calculated copper content is $2.5 \%$, the higher amount of copper $(4.3 \%)$ in $\mathrm{Cu}^{2+}-$ montmorillonite might be explained by the formation of copper oxyhydroxide oligomers, which could lower the charge of copper ions (Tanaka et al., 2007). The copper content in synthesized ZVCMMT decreased to $3.3 \%(\mathrm{w} / \mathrm{w})$ (Tab. S1), probably due to the loss of copper in the washing steps during preparation, this phenomenon was also observed for preparing subnano-sized ZVI in montmorillonite (Gu et al., 2010).

With the addition of $\mathrm{NaBH}_{4}$, clay suspension turned into black immediately indicating the formation of ZVC. As shown in the XRD measurements (Fig. 1), the basal spacing of montmorillonite increases from $13.89 \AA\left(\mathrm{Cu}^{2+}\right.$-montmorillonite $)$ to 
$14.72 \AA$ after reduction at $\mathrm{NaBH}_{4} / \mathrm{Cu}^{2+}$ molar ratio of 15 , which further increases to $15.71 \AA$ with the increase of $\mathrm{NaBH}_{4} / \mathrm{Cu}^{2+}$ ratio of 30 . Similar to our previous observation ( $\mathrm{Gu}$ et al., 2010), the increase of basal spacing of clay mineral is attributed to the formation of nZVC clusters in clay interlayer. Considering that the thickness of aluminosilicate layer of montmorillonite is $9.6 \AA$ (Malla et al., 1991), the synthesized particle size in the vertical dimension is $\sim 6 \AA$, which is much smaller than other forms of nZVCs reported in the literatures (Liou et al., 2007; Huang et al., 2012; Dong et al., 2014). The TEM image of synthesized ZVCMMT, and copper/silicon mapping in the same area are shown in Figure S1, it is indicated that the distribution of $\mathrm{Cu}$ follows the same pattern as $\mathrm{Si}$, suggesting that the copper particles are formed homogeneously on the surface of montmorillonite (Yu et al., 2012).

Based on the XPS analysis (Fig. 2), the copper species in the original $\mathrm{Cu}^{2+}$-montmorillonite is $\mathrm{Cu}^{2+}(935.5 \mathrm{eV})$ (Koppelman and Dillard, 1977). A strong peak corresponding to $\mathrm{Cu}^{+}(933.2 \mathrm{eV})$ was also observed, which is consistent with the results of Cai and Xue (Cai and Xue, 2008), and can be explained by the photo-reduction process induced with the X-ray irradiation. After $\mathrm{NaBH}_{4}$ reduction, most of copper turns into ZVC $(932.2 \mathrm{eV})$, with a small shift compared to the standard binding energy of $\mathrm{Cu}^{0}(932.4 \mathrm{eV})$ due to the small particle size effect (Oberli et al., 1981). The metal surface is slightly oxidized by oxygen, as evidenced by the cupric hydroxide shoulder at $934.4 \mathrm{eV}$ (Jiang et al., 2013). 


\subsection{Degradation of atrazine by ZVCMMTs, $\mathrm{ZZVC}$ and commercial available}

\section{ZVC}

Control experiments show that the degradation of atrazine in the absence of ZVC and ZVCMMTs is negligible under the experimental conditions, suggesting that atrazine is resistant to photo-degradation and volatilization (Fig. S2). According to our results, the degradation of atrazine by ZVCMMT is strongly pH dependent (Fig. S3). For the initial $\mathrm{pH}$ range between 3 and 6 , the initial removal rate of atrazine for freshly prepared ZVCMMT decreases from $0.549 \mu \mathrm{M} \min ^{-1}$ at $\mathrm{pH} 3$ to $0.001 \mu \mathrm{M}$ $\min ^{-1}$ at pH 6 (Tab. 1). Previous studies had demonstrated that acidic condition would facilitate the formation of $\mathrm{H}_{2} \mathrm{O}_{2}$ and subsequent hydroxyl radical, favoring the Fenton-like reactions (Masarwa et al., 2005; Gang et al., 2014). Concomitantly, as shown in EPR results (Fig. 3), when the $\mathrm{pH}$ increases from 3 to 6, the detected EPR signal changes from DMPO--OH to the carbon center radical, which is generated from the reaction between DMPO and $\cdot \mathrm{O}_{2}{ }^{-}$(Wang et al., 2013; Dong et al., 2014). Our experimental results further indicate that atrazine could not be degraded by $\cdot \mathrm{O}_{2}{ }^{-}$ radicals (Fig. S4), and when the reaction is quenched with methanol, the degradation process is significantly suppressed (Fig. S2), which confirms that $\cdot \mathrm{OH}$ is the predominant ROS for degradation of atrazine.

The subsequent studies were all performed at initial $\mathrm{pH}$ of 3 to investigate the underlying mechanisms for the extraordinary reactivity of natural clay templated ZVC. 
As shown in Figure 4, the initial hydration status of ZVCMMT substantially affects

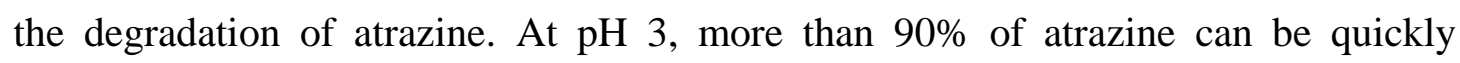
degraded by the freeze dried ZVCMMT within 2 min (Fig. 4), which was also supported by the high $\mathrm{H}_{2} \mathrm{O}_{2}$ concentration detected in the beginning of the reaction in the presence of the freeze dried ZVCMMT (Fig. S5). Whereas, for the reaction system with freshly prepared ZVCMMT, the initial degradation rate decreases nearly 12 times compared to freeze dried ZVCMMT (Tab. 1). The final pHs for freeze dried and freshly prepared ZVCMMT systems are 3.65 and 3.63, respectively. It has been reported that the hydration and swelling situation of clay mineral could substantially affect the adsorption of atrazine onto clay surfaces (Chappell et al., 2005). As indicated in Figure S6, the freeze dried montmorillonite has much greater affinity for atrazine than fresh $\mathrm{Na}^{+}$-montmorillonite with $\sim 2$ order of magnitude higher for the adsorption coefficient (Tab. S2), which could be explained that since dried montmorillonite is less hydrated and atrazine can form direct interaction with the opposing basal surface of the clay mineral (Chappell et al., 2005). The enhanced adsorption of atrazine on montmorillonite would increase the contact possibility between atrazine and $\mathrm{ZVC}$, hence increasing the degradation rate, similar phenomenon has also been observed in our previous studies (Gu et al., 2010; Yu et al., 2012; Tian et al., 2015). In addition, other factors may also contribute to the higher reactivity for freeze dried ZVCMMT. As we have mentioned, oxygen is essential to 
produce ROS. For freeze dried ZVCMMT, due to the oxygen residue retained on the surface of mineral, the reaction can be quickly initiated. However, for freshly prepared ZVCMMT, during the reduction by $\mathrm{NaBH}_{4}$, the oxygen on the mineral surface has been quickly consumed by the strong reductant. Therefore, the degradation reaction is slowed down due to the slow diffusion of oxygen into the system. To further support this hypothesis, the degradation experiments were conducted inside an anaerobic chamber. There was negligible degradation of atrazine (less than $3.3 \%$ ) observed in the freshly prepared ZVCMMT system, whereas, for freeze dried ZVCMMT, a quick degradation occurred in the first few min, then the reaction leveled out, indicating that there is some oxygen to initiate the reaction and no further oxygen input to sustain the degradation (Fig. S2).

For comparison, the degradation experiments by commercial available ZVC, nZVC were also conducted. Even the copper concentrations for both ZVC and nZVC (0.5 $\left.\mathrm{g} \mathrm{L}^{-1}\right)$ are much higher than the copper content in ZVCMMT $\left(\sim 0.0175 \mathrm{~g} \mathrm{~L}^{-1}\right)$ system used in this study, only $20 \%$ and $60 \%$ of atrazine with the initial concentration of $15 \mu \mathrm{M}$ can be degraded in $3 \mathrm{~h}$ for $\mathrm{ZVC}$ and $\mathrm{nZVC}$. On the other hand, atrazine can be fully degraded within 2 and $120 \mathrm{~min}$ for freeze dried and freshly prepared ZVCMMT, respectively (Fig. 4). The high reactivity of ZVCMMT is attributable to the small particle size of ZVC with high surface area. Due to the constrained clay interlayer space, the size of formed ZVC in the vertical dimension is $\sim 0.6 \mathrm{~nm}$ based 
on the XRD results (Fig. 1). However, for $\mathrm{nZVC}$, the average diameter of ZVC particles is $\sim 25 \mathrm{~nm}$, which could then form aggregates with the size even larger than several micrometers (Fig. S7). In addition, the final $\mathrm{pHs}$ for $\mathrm{nZVC}$ and commercially available ZVC systems with initial $\mathrm{pH}$ of 3 are 5.79 and 6.57 , respectively. When $\cdot \mathrm{OH}$ radical or $\mathrm{O}_{2}$ reacts with $\mathrm{nZVC}$ or $\mathrm{ZVC}$, the layer of copper hydroxide might be formed on the surface at higher $\mathrm{pH}$, preventing further reactions with the copper core, which could explain why the reaction stops for commercial available ZVC and nZVC even there is sufficient copper available. It is also supported from the dark-field TEM and EDS images of nZVC, as shown in Figure S8, after the reaction, the copper core is surrounded with amorphous copper oxide. In the dark-field image, the bright and dark areas represent metallic and oxidized copper, respectively (Fig. S8), which is in agreement with the results of LaGrow and his co-workers (LaGrow et al., 2016). In addition, as indicated in Table S4, ZVCMMT has the highest BET surface area (120.43 $\left.\mathrm{m}^{2} \mathrm{~g}^{-1}\right)$ among the materials tested, suggesting that ZVCMMT could provide more reactive sites for the degradation of atrazine.

The release of copper ions was observed in our ZVCMMT systems, after 3h, the measured copper concentration in solution is $7.85 \mathrm{mg} \mathrm{L}^{-1}$. While for $\mathrm{nZVC}$ and commercially available ZVC, the released copper concentrations are $47.6,50.2 \mathrm{mg} \mathrm{L}^{-1}$, respectively. So lower release of cupper is another benefit for ZVCMMT, which can be explained that the negatively charged surface of MMT could retain the released 
copper ions by electron static adsorption. The elevated copper level could be further reduced by adjusting solution $\mathrm{pH}$ to neutral before discharge, our results also showed that the copper was undetectable at $\mathrm{pH} 7$ in our system. Stability of ZVCMMT was also evaluated after this material was stored for $7 \mathrm{~d}$ and $14 \mathrm{~d}$ in a desiccator, no significant decrease of reactivity was observed (Fig S14).

Compared to ZVCMMT, only limited degradation (17.48\%) of atrazine was observed in the presence of ZVIMMT. At $\mathrm{pH} 3$, ZVI can be consumed by protons, the production of hydrogen gas was also detected (Fig. S13). However, in the system of ZVCMMT, no $\mathrm{H}_{2}$ was produced (Fig. S13).

\subsection{Proposed degradation mechanism of atrazine}

As shown in the HPLC chromatogram (Fig. S9), according to the retention time of the available standards, the peaks at $8.131,15.805$ and 21.036 min correspond to DEDIA, DIA and DEA, respectively. Furthermore, the peak at $29.55 \mathrm{~min}$ is assigned to 2-chloro-4-ethylimino-6-isopropylamino-s-triazine (atrazine-imine) according to the results reported by Acero and his co-workers (Acero et al., 2000). In addition, 4-acetamido-2-chloro-6-isopropylamino-s-triazine $\quad$ (CDIT) and 4-acetamido-6-amino-2-chloro-s-triazine (CDAT) were also detected by GC-MS analysis (Fig. S10). Based on the reaction products identified in our experiment and the structures of intermediates reported in the prior studies, the degradation pathway of atrazine by ZVCMMT is proposed in Figure 5. Initially, $\cdot \mathrm{OH}$ is produced via the 
activation of oxygen molecule by ZVC, then the radical would attack the aliphatic side chains of atrazine. With the cleavage of N-C bond, DIA and DEA are produced, and subsequently forming DEDIA. Similar products were observed in the previous studies (Hu et al., 2012; Marchetti et al., 2013). On the other hand, a carbon centered radical can also be formed via a H-abstraction process (von Sonntag and Schuchmann, 1991; Acero et al., 2000). When the carbon radical reacts with oxygen, an organic peroxyl radical is produced, then yielding $\mathrm{C}=\mathrm{N}$ and $\mathrm{C}=\mathrm{O}$ bonds at the $\alpha$ carbon via a mono or bimolecular reaction to form atrazine-imine, CDIT, and CDIA, respectively.

Theoretical calculations were used to help interpret the degradation mechanism of atrazine. The electron density was visualized by exhibition of isosurfaces with LOMO and HOMO frontier orbitals (Fig. S11). It was reported that the values of $2 \mathrm{FED}^{2}$ номо and $\mathrm{FED}_{\mathrm{HOMO}}^{2}+\mathrm{FED}_{\text {LUMO }}^{2}$ can characterize the potential of the reactive sites for electron extraction and $\cdot \mathrm{OH}$ addition, respectively (Lee et al., 2001; Qu et al., 2015), and the degradation of atrazine mainly occurs on the side chain of the molecule (Yang et al., 2016). Nitrogen 3 and nitrogen 11 have higher $2 \mathrm{FED}_{\text {Hомо }}^{2}$ and

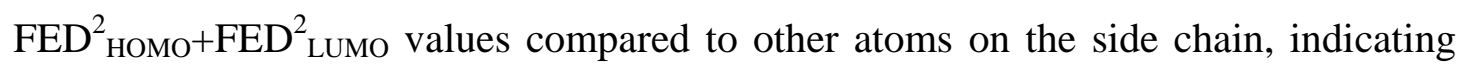
that these two sites would be involved in the degradation process, which is consistent with our experimental results.

\subsection{Toxicity assay}

The toxicity of the system was evaluated by the inhibition of light emission of 
Vibrio fischeri. Before the reaction, the inhibition value for $15 \mu \mathrm{M}$ atrazine is $24.95 \%$, whereas, after the 180 min reaction with the freeze dried ZVCMMT, the inhibition becomes negligible $(-0.53 \%)$. The significant decrease of the toxicity can be explained by the fast decomposition of atrazine and formation of less toxic intermediates, e.g., DIA and DEA. Similar results were also observed by Ralston-Hooper and his co-workers (Ralston-Hooper et al., 2009), the degradation products show lower toxicity compared to atrazine when algae was used as the indicator.

\section{Conclusions}

In this study, natural montmorillonite templated ZVC was synthesized by intercalating $\mathrm{Cu}^{0}$ into clay interlayer, the unique structure of clay mineral could effectively prevent the aggregation of ZVC particles and inhibit particle growth. The particle size of ZVCMMT is 1 or 2 order of magnitude smaller than nZVC prepared by the conventional method. The ZVCMMT exhibits high reactivity for degradation of organic contaminant, i.e., atrazine by activation of oxygen to form reactive hydroxyl radical.

This material can be considered as a promising technique for water treatment, a burst of hydroxyl radical can be produced on the surface of ZVCMMT in a short time without addition of any hydrogen peroxide. It provides a convenient and efficient alternative for rapid degradation of persistent contaminants. Since montmorillonite has been widely used as the clay barrier for waste disposal, the ZVCMMT can be 
incorporated as the reactive cap for in situ remediation of many organic pollutants.

Further studies are needed to investigate the effect of other environmental factors, e.g., the presence of humic substances and competing ions on the degradation process for field application of this novel material.

\section{Acknowledgments}

This work was financially supported by the National Key Basic Research Program of China (2014CB441102), National Science Foundation of China (grants 21237002 and 21477051), and the Collaborative Innovation Center for Regional Environmental Quality.

\section{Appendix A. Supplementary data}

GC-MS Method; SPE Method; Total copper contents of montmorillonite saturated with $\mathrm{Na}^{+} / \mathrm{Cu}^{2+}$ and the freeze dried ZVCMMT; Fitted linear adsorption coefficients for atrazine adsorption on $\mathrm{Na}^{+}$-montmorillonite with different hydration status; TEM image of ZVCMMT and elemental distribution mapping of $\mathrm{Si}$ and $\mathrm{Cu}$ of the same region; Degradation kinetics of atrazine under different control conditions; Degradation kinetics of atrazine with freshly prepared ZVCMMT at various pHs; Concentrations of atrazine before and after reaction with superoxide radicals; Hydrogen peroxide generation vs time by ZVCMMTs, nZVC, and commercially available ZVC; Atrazine adsorption on $\mathrm{Na}^{+}$-montmorillonite with different hydration status; TEM image of synthesized nZVC; TEM image of nZVC after reaction and copper distribution in the same region; HPLC chromatograms of atrazine and its metabolites after reaction; GC-MS chromatograms of atrazine standard and its metabolites after reaction; Frontier electron densities of atrazine. Supplementary data related to this article can be found at https://www.journals.elsevier.com/chemosphere/. 


\section{References}

Acero, J.L., Stemmler, K., Von Gunten, U., 2000. Degradation kinetics of atrazine and its degradation products with ozone and $\mathrm{OH}$ radicals: a predictive tool for drinking water treatment. Environ. Sci. Technol. 34, 591-597.

Balogh, L., Tomalia, D.A., 1998. Poly(amidoamine) dendrimer-templated nanocomposites. 1. synthesis of zerovalent copper nanoclusters. J. Am. Chem. Soc. 120, 7355-7356.

Buxton, G.V., Greenstock, C.L., Helman, W.P., Ross, A.B., 1988. Critical review of rate constants for reactions of hydrated electrons, hydrogen atoms and hydroxyl radicals $\left(\cdot \mathrm{OH}^{-} \cdot \mathrm{O}^{-}\right)$in aqueous solution. J. Phys. Chem. Ref. Data 17, 513-886.

Cai, Y.F., Xue, J.Y., 2008. A study of adsorption and absorption mechanisms of copper in palygorskite. Clay Minerals 43, 195-203.

Chappell, M.A., Laird, D.A., Thompson, M.L., Li, H., Teppen, B.J., Aggarwal, V., Johnston, C.T., Boyd, S.A., 2005. Influence of smectite hydration and swelling on atrazine sorption behavior. Environ. Sci. Technol. 39, 3150-3156.

Dadgostar, N., Ferdous, S., Henneke, D., 2010. Colloidal synthesis of copper nanoparticles in a two-phase liquid-liquid system. Mater. Lett. 64, 45-48.

Dong, G.H., Ai, Z.H., Zhang, L.Z., 2014. Total aerobic destruction of azo contaminants with nanoscale zero-valent copper at neutral $\mathrm{pH}$ : Promotion effect of in-situ generated carbon center radicals. Water Res. 66, 22-30.

Dries, J., Bastiaens, L., Springael, D., Kuypers, S., Agathos, S.N., Diels, L., 2005. Effect of humic 
acids on heavy metal removal by zero-valent iron in batch and continuous flow column systems. Water Res. 39, 3531-3540.

Englehardt, J.D., Meeroff, D.E., Echegoyen, L., Deng, Y., Raymo, F.M., Shibata, T., 2007. Oxidation of aqueous EDTA and associated organics and coprecipitation of inorganics by ambient iron-mediated aeration. Environ. Sci. Technol. 41, 270-276.

Enoch, R.R., Stanko, J.P., Greiner, S.N., Youngblood, G.L., Rayner, J.L., Fenton, S.E., 2007. Mammary gland development as a sensitive end point after acute prenatal exposure to an atrazine metabolite mixture in female long-evans rats. Environ. Health Perspect. 115, $541-547$.

Frisch, M.J.T., G. W.; Schlegel, H. B.; Scuseria, G. E.;, Robb, M.A.C., J. R.; Scalmani, G.; Barone, V.; Mennucci,, B.; Petersson, G.A.N., H.; Caricato, M.; Li, X.; Hratchian, H., P.; Izmaylov, A.F.B., J.; Zheng, G.; Sonnenberg, J. L.; Hada, M.;, Ehara, M.T., K.; Fukuda, R.; Hasegawa, J.; Ishida, M.; Nakajima,, T.; Honda, Y.K., O.; Nakai, H.; Vreven, T.; Montgomery, J. A., Jr.;, Peralta, J.E.O., F.; Bearpark, M.; Heyd, J. J.; Brothers, E.; Kudin,, K. N.; Staroverov, V.N.K., R.; Normand, J.; Raghavachari, K.;, Rendell, A.B., J. C.; Iyengar, S. S.; Tomasi, J.; Cossi, M.; Rega,, N.; Millam, J.M.K., M.; Knox, J. E.; Cross, J. B.; Bakken, V.; Adamo, C.J., J.; Gomperts, R.; Stratmann, R. E.; Yazyev, O.;, Austin, A.J.C., R.; Pomelli, C.; Ochterski, J. W.; Martin, R. L.; Morokuma, K.Z., V. G.; Voth, G. A.; Salvador, P.;, Dannenberg, J.J.D., S.; Daniels, A. D.; Farkas, O.; Foresman, J.B.O., J. V.; Cioslowski, J.; Fox, D. J., 2009. Gaussian 09, revision A.02; Gaussian, Inc.: Wallingford, CT. 
Gang, W., Sheng, J.W., Jun, M., Ting, L.H., Zheng, Q.L., Lei, Z., Jin, L.X., 2014. Oxidative degradation of organic pollutants in aqueous solution using zero valent copper under aerobic atmosphere condition. J. Hazard. Mater. 275, 193-199.

Ghosh, P.K., Philip, L., 2004. Atrazine degradation in anaerobic environment by a mixed microbial consortium. Water Res. 38, 2277-2284.

Gu, C., Jia, H., Li, H., Teppen, B.J., Boyd, S.A., 2010. Synthesis of highly reactive subnano-sized zero-valent iron using smectite clay templates. Environ. Sci. Technol. 44, 4258-4263.

Gu, C., Li, H., Teppen, B.J., Boyd, S.A., 2008. Octachlorodibenzodioxin formation on Fe(III)-montmorillonite clay. Environ. Sci. Technol. 42, 4758-4763.

Guan, Y.H., Ma, J., Ren, Y.M., Liu, Y.L., Xiao, J.Y., Lin, L.Q., Zhang, C., 2013. Efficient degradation of atrazine by magnetic porous copper ferrite catalyzed peroxymonosulfate oxidation via the formation of hydroxyl and sulfate radicals. Water Res. 47, 5431-5438.

Hu, E., Cheng, H., 2014. Catalytic effect of transition metals on microwave-induced degradation of atrazine in mineral micropores. Water Res. 57, 8-19.

Hu, E.D., Cheng, H.F., Hu, Y.N., 2012. Microwave-induced degradation of atrazine sorbed in mineral micropores. Environ. Sci. Technol. 46, 5067-5076.

Huang, C.C., Lo, S.L., Lien, H.L., 2012. Zero-valent copper nanoparticles for effective dechlorination of dichloromethane using sodium borohydride as a reductant. Chem. Eng. J. 203, 95-100.

Huang, C.C., Lo, S.L., Tsai, S.M., Lien, H.L., 2011. Catalytic hydrodechlorination of 1,2-dichloroethane using copper nanoparticles under reduction conditions of sodium 26 
borohydride. J. Environ. Monit. 13, 2406-2412.

Huang, X., Dai, J., Fournier, J., Ali, A.M., Zhang, Q., Frenkel, K., 2002. Ferrous ion autoxidation and its chelation in iron-loaded human liver HepG2 cells. Free Radic. Biol. Med. 32, 84-92.

Jacqueline, Q., Cherie, G., Chris, C., Kathleen, B., Christina, C., Suzanne, O.H., Thomas, K., David, M., Woong-Sang, Y., Arun, G., Thomas, H., 2005. Field demonstration of DNAPL dehalogenation using emulsified zero-valent iron. Environ. Sci. Technol. 39, 1309-1318.

Jiang, P., Prendergast, D., Borondics, F., Porsgaard, S., Giovanetti, L., Pach, E., Newberg, J., Bluhm, H., Besenbacher, F., Salmeron, M., 2013. Experimental and theoretical investigation of the electronic structure of $\mathrm{Cu}_{2} \mathrm{O}$ and $\mathrm{CuO}$ thin films on $\mathrm{Cu}(110)$ using $\mathrm{x}$-ray photoelectron and absorption spectroscopy. J. Chem. Phys. 138, 024704(024701-024706).

Joo, S.H., Feitz, A.J., Sedlak, D.L., Waite, T.D., 2004. Quantification of the oxidizing capacity of nanoparticulate zero-valent iron. Environ. Sci. Technol. 39, 1263-1268.

Katsoyiannis, I.A., Ruettimann, T., Hug, S.J., 2008. pH dependence of Fenton reagent generation and As(III) oxidation and removal by corrosion of zero valent iron in aerated water. Environ. Sci. Technol. 42, 7424-7430.

Keenan, C.R., Sedlak, D.L., 2008a. Factors affecting the yield of oxidants from the reaction of nanoparticulate zero-valent iron and oxygen. Environ. Sci. Technol. 42, 1262-1267.

Keenan, C.R., Sedlak, D.L., 2008b. Ligand-enhanced reactive oxidant generation by nanoparticulate zero-valent iron and oxygen. Environ. Sci. Technol. 42, 6936-6941.

Khanna, P.K., Gaikwad, S., Adhyapak, P.V., Singh, N., Marimuthu, R., 2007. Synthesis and 
characterization of copper nanoparticles. Mater. Lett. 61, 4711-4714.

Kim, H.-H., Lee, H., Kim, H.-E., Seo, J., Hong, S.W., Lee, J.-Y., Lee, C., 2015. Polyphosphate-enhanced production of reactive oxidants by nanoparticulate zero-valent iron and ferrous ion in the presence of oxygen: yield and nature of oxidants. Water Res. 86, 66-73.

Koppelman, M.H., Dillard, J.G., 1977. A study of the adsorption of Ni(II) and $\mathrm{Cu}(\mathrm{II})$ by clay minerals. Clays and Clay Minerals 25, 457-462.

LaGrow, A.P., Ward, M.R., Lloyd, D.C., Gai, P.L., Boyes, E.D., 2016. Visualizing the Cu/Cu2O Interface Transition in Nanoparticles with Environmental Scanning Transmission Electron Microscopy. J. Am. Chem. Soc.

Laszlo, P., 1987. Chemical reactions on clays. Science 235, 1473-1477.

Lee, B.D., Iso, M., Hosomi, M., 2001. Prediction of Fenton oxidation positions in polycyclic aromatic hydrocarbons by frontier electron density. Chemosphere 42, 431-435.

Liou, Y.H., Lo, S.L., Lin, C.J., 2007. Size effect in reactivity of copper nanoparticles to carbon tetrachloride degradation. Water Res. 41, 1705-1712.

Liu, T., Tsang, D.C.W., Lo, I.M.C., 2008. Chromium(VI) reduction kinetics by zero-valent iron in moderately hard water with humic acid: iron dissolution and humic acid adsorption. Environ. Sci. Technol. 42, 2092-2098.

Malla, P.B., Ravindranathan, P., Komarneni, S., Roy, R., 1991. Intercalation of copper metal-clusters in montmorillonite. Nature 351, 555-557.

Marchetti, G., Minella, M., Maurino, V., Minero, C., Vione, D., 2013. Photochemical transformation of 28 
atrazine and formation of photointermediates under conditions relevant to sunlit surface waters: Laboratory measures and modelling. Water Res. 47, 6211-6222.

Masarwa, A., Rachmilovich-Calis, S., Meyerstein, N., Meyerstein, D., 2005. Oxidation of organic substrates in aerated aqueous solutions by the Fenton reagent. Coord. Chem. Rev. 249, 1937-1943.

Oberli, L., Monot, R., Mathieu, H.J., Landolt, D., Buttet, J., 1981. Auger and x-ray photoelectron-spectroscopy of small Au particles. Surf. Sci. 106, 301-307.

Pearson, C.R., Hozalski, R.M., Arnold, W.A., 2005. Degradation of chloropicrin in the presence of zero-valent iron. Environ. Toxicol. Chem. 24, 3037-3042.

Pinnavaia, T.J., 1983. Intercalated clay catalysts. Science 220, 365-371.

Ponder, S.M., Darab, J.G., Mallouk, T.E., 2000. Remediation of $\mathrm{Cr}(\mathrm{VI})$ and $\mathrm{Pb}(\mathrm{II})$ aqueous solutions using supported, nanoscale zero-valent iron. Environ. Sci. Technol. 34, 2564-2569.

Qu, R.J., Feng, M.B., Wang, X.H., Huang, Q.G., Lu, J.H., Wang, L.S., Wang, Z.Y., 2015. Rapid removal of tetrabromobisphenol A by ozonation in Water: oxidation products, reaction pathways and toxicity assessment. Plos One 10, 1-17.

Ralston-Hooper, K., Hardy, J., Hahn, L., Ochoa-Acuna, H., Lee, L.S., Mollenhauer, R., Sepulveda, M.S., 2009. Acute and chronic toxicity of atrazine and its metabolites deethylatrazine and deisopropylatrazine on aquatic organisms. Ecotoxicology 18, 899-905.

Stanko, J.P., Enoch, R.R., Rayner, J.L., Davis, C.C., Wolf, D.C., Malarkey, D.E., Fenton, S.E., 2010. Effects of prenatal exposure to a low dose atrazine metabolite mixture on pubertal timing and 
prostate development of male Long-Evans rats. Reprod. Toxicol. 30, 540-549.

Stephen, J.M., Li, M., David, A.C., Roy, F.S., 1998. Confirmation and method development for dechlorinated atrazine from reductive dehalogenation of atrazine with $\mathrm{Fe}^{0}$. Anal. Chim. Acta $373,153-160$.

Tanaka, M., Itadani, A., Abe, T., Taguchi, H., Nagao, M., 2007. Observation of characteristic IR band assignable to dimerized copper ions in montmorillonite. J. Colloid Interface Sci. 308, 285-288.

Tian, H., Guo, Y., Pan, B., Gu, C., Li, H., Boyd, S.A., 2015. Enhanced photoreduction of nitro-aromatic compounds by hydrated electrons derived from indole on natural montmorillonite. Environ. Sci. Technol. 49, 7784-7792.

von Sonntag, C., Schuchmann, H.-P., 1991. The elucidation of peroxyl radical reactions in aqueous solution with the help of radiation-chemical methods. Angewandte Chemie International Edition in English 30, 1229-1253.

Vonberg, D., Hofmann, D., Vanderborght, J., Lelickens, A., Koeppchen, S., Puetz, T., Burauel, P., Vereecken, H., 2014. Atrazine soil core residue analysis from an agricultural field 21 years after its ban. J. Environ. Qual. 43, 1450-1459.

Wang, L., Cao, M., Ai, Z., Zhang, L., 2014. Dramatically enhanced aerobic atrazine degradation with $\mathrm{Fe} @ \mathrm{Fe}_{2} \mathrm{O}_{3}$ core-shell nanowires by tetrapolyphosphate. Environ. Sci. Technol. 48, 3354-3362.

Wang, L., Wang, F., Li, P., Zhang, L., 2013. Ferrous-tetrapolyphosphate complex induced dioxygen activation for toxic organic pollutants degradation. Sep. Purif. Technol. 120, 148-155.

Yang, H., Wei, H., Hu, L., Liu, H., Yang, L., Au, C., Yi, B., 2016. Mechanism for the photocatalytic 
transformation of $s$-triazine herbicides by $\mathrm{OH}$ radicals over $\mathrm{TiO}_{2}$. Chem. Eng. J. 300, 209-216.

Yu, K., Gu, C., Boyd, S.A., Liu, C., Sun, C., Teppen, B.J., Li, H., 2012. Rapid and extensive debromination of decabromodiphenyl ether by smectite clay-templated subnanoscale zero-valent iron. Environ. Sci. Technol. 46, 8969-8975.

Zhang, Q., Guo, Y., Huang, M., Li, H., Gu, C., 2015. Degradation of selected polychlorinated biphenyls by montmorillonite clay-templated $\mathrm{Fe}^{0} / \mathrm{Ni}^{0}$ bimetallic system. Chem. Eng. J. 276, 122-129. 
Table 1. Initial removal rate of atrazine with different forms of $\mathrm{ZVC}$ at different pH

\begin{tabular}{cccc}
\hline & \multicolumn{3}{c}{ Initial removal rate $\left(\mu \mathrm{M} \mathrm{min}^{-1}\right)$} \\
\hline$p H$ & 3.0 & 4.5 & 6.0 \\
\hline Freshly prepared ZVCMMT & 0.549 & 0.222 & 0.001 \\
Freeze dried ZVCMMT & 6.909 & 2.143 & 0.608 \\
nZVC & 3.255 & 0.441 & 0.038 \\
Commercially available ZVC & 0.096 & 0.271 & 0.021 \\
\hline
\end{tabular}

Initial rate was defined as the change of the concentration of atrazine in the first two min of the reactions. Experimental conditions: the initial concentration of atrazine and the solid materials were $15 \mu \mathrm{M}$ and $0.5 \mathrm{~g} \mathrm{~L}^{-1}$, respectively; the initial $\mathrm{pH}$ was adjusted to 3, 4.5, and 6 with $\mathrm{HClO}_{4}(1 \mathrm{M})$ and $\mathrm{NaOH}(1 \mathrm{M})$. 


\section{Figure Legends}

Figure 1. X-ray diffraction patterns of $\mathrm{Cu}^{2+}$-montmorillonite and $\mathrm{Cu}^{0}$-montmorillonite after treatment by $\mathrm{NaBH}_{4}$ at $\mathrm{NaBH}_{4} / \mathrm{Cu}^{2+}$ ratio of 15 and 30, respectively.

Figure 2. Fitted curve of narrow XPS scans for $\mathrm{Cu}\left(2 \mathrm{p}_{3 / 2}\right)$ of $\mathrm{Cu}^{2+}$-montmorillonite and the freeze dried ZVCMMT. Solid black lines are the fitted curves. Wavy-like lines are the observed photoelectron curves.

Figure 3. EPR spectra of freeze dried ZVCMMT at pH 3.0 (top) and $\mathrm{pH} 6.2$ (bottom), DMPO was used as the effective radical scavenger. Experimental conditions: $\mathrm{pH}$ was adjusted to 3.0 or 6.2 with $\mathrm{HClO}_{4}(1 \mathrm{M})$ or $\mathrm{NaOH}(1 \mathrm{M})$; the concentration of DMPO and the freeze dried ZVCMMT were $40 \mathrm{mM}$ and $0.5 \mathrm{~g} \mathrm{~L}^{-1}$, respectively.

Figure 4. Degradation kinetics of atrazine by different forms of ZVC. Experimental conditions: the initial concentrations of atrazine and different materials were $15 \mu \mathrm{M}$ and $0.5 \mathrm{~g} \mathrm{~L}^{-1}$. The initial $\mathrm{pH}$ was adjusted to 3.0 with $\mathrm{HClO}_{4}(1 \mathrm{M})$. Three reactors were sampled for each time point, and the data were averaged. Error bars represent the standard deviations.

Figure 5. Proposed degradation pathway of atrazine in the reaction system. 


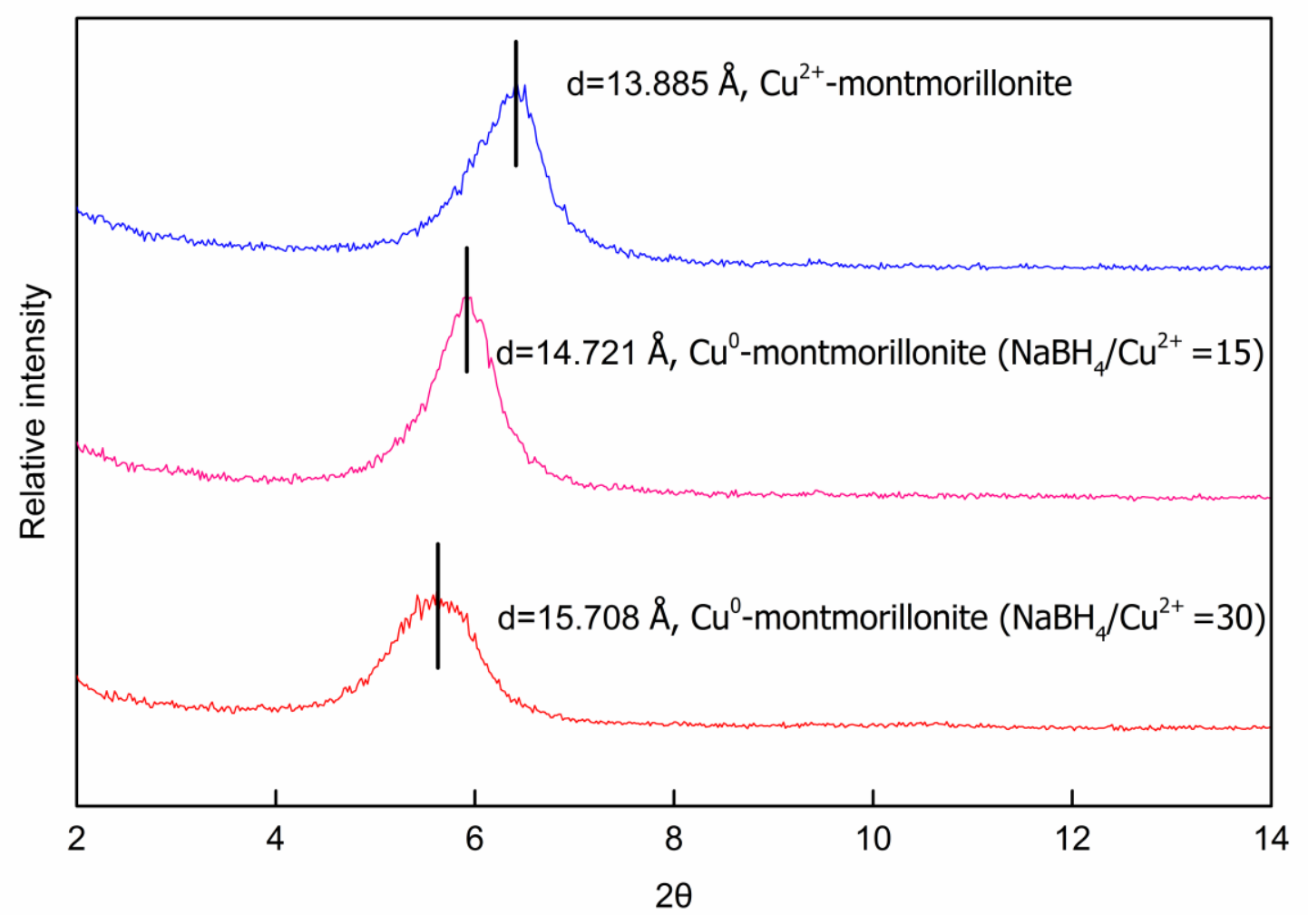

Fig. 1 


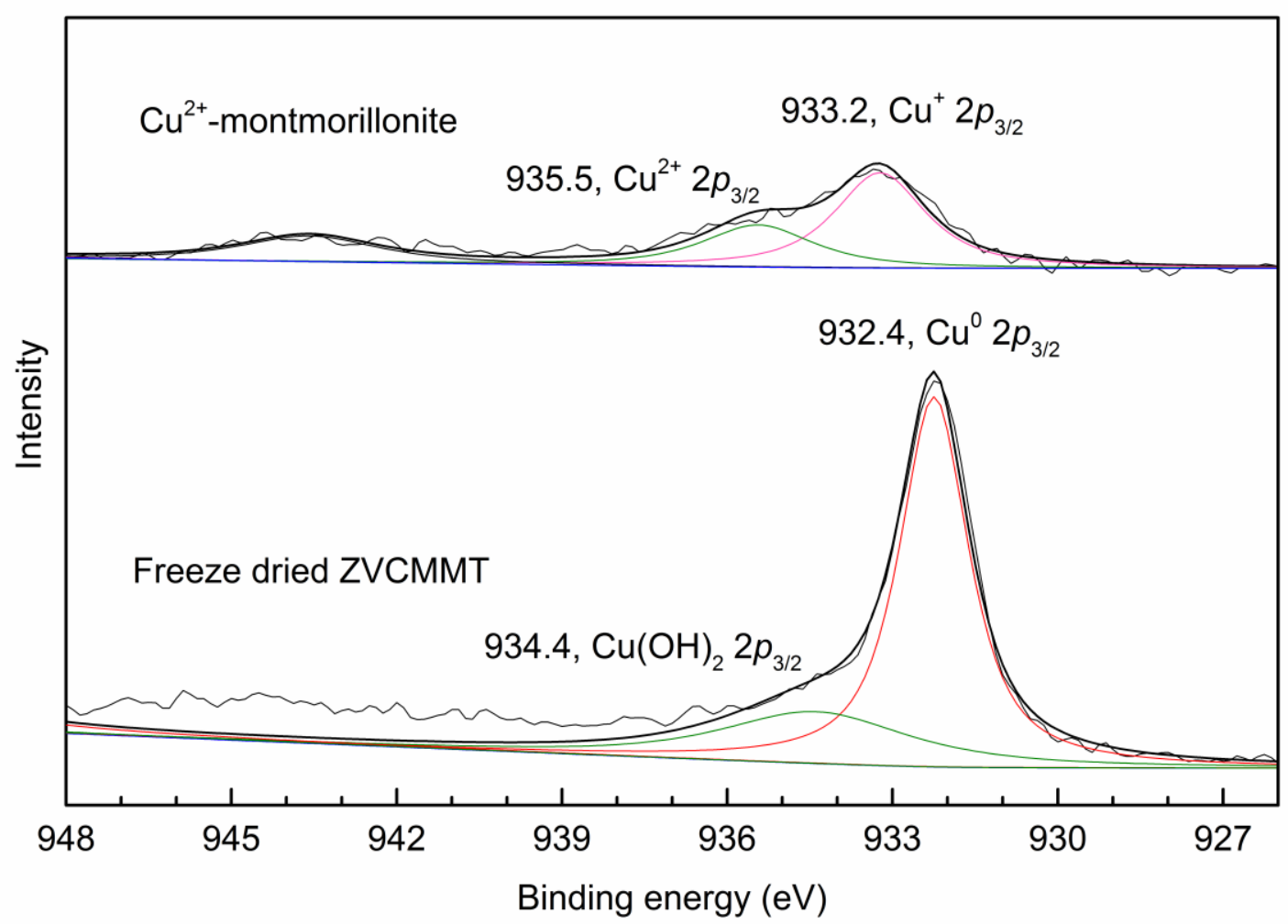

Fig. 2 


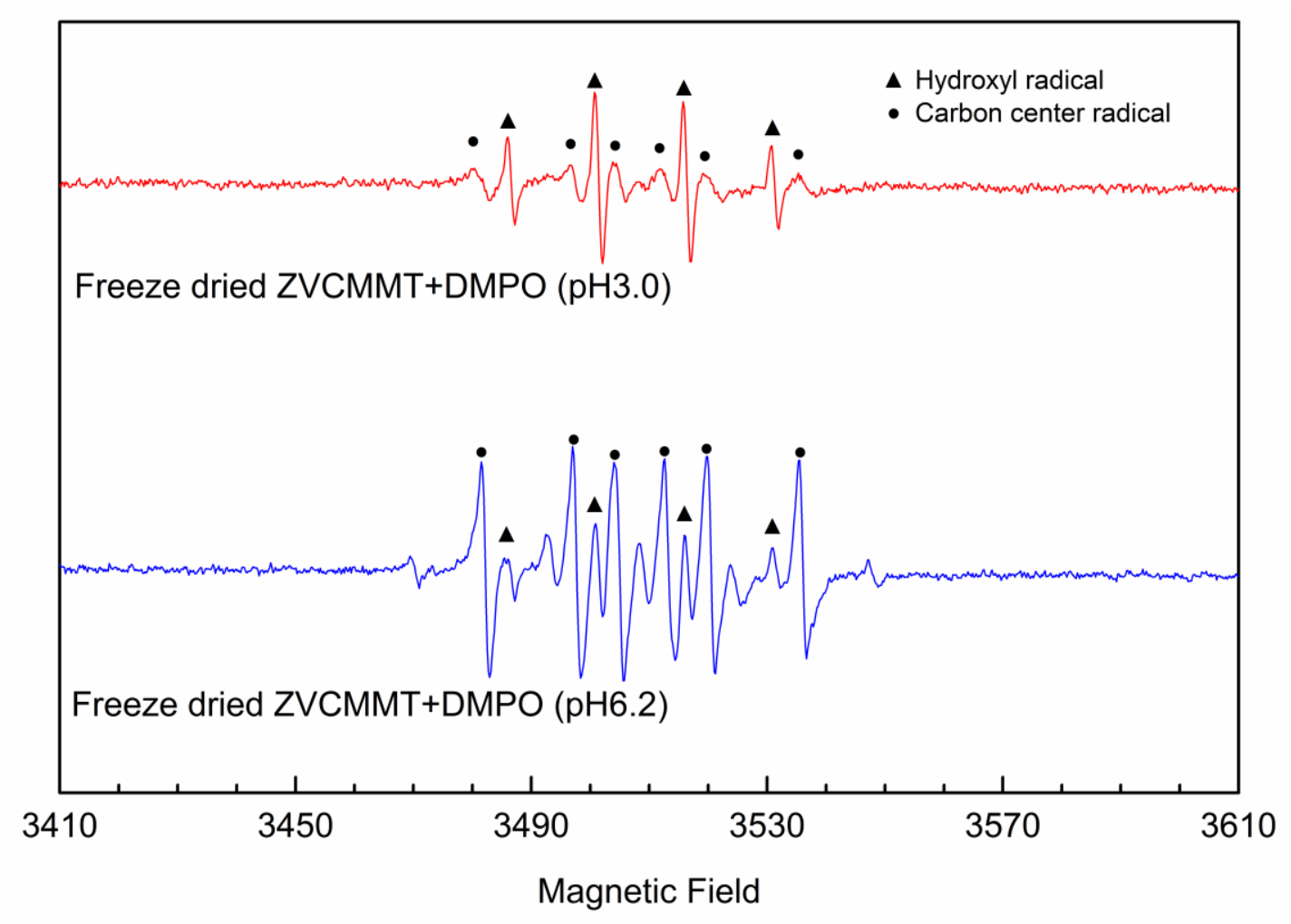

Fig. 3 


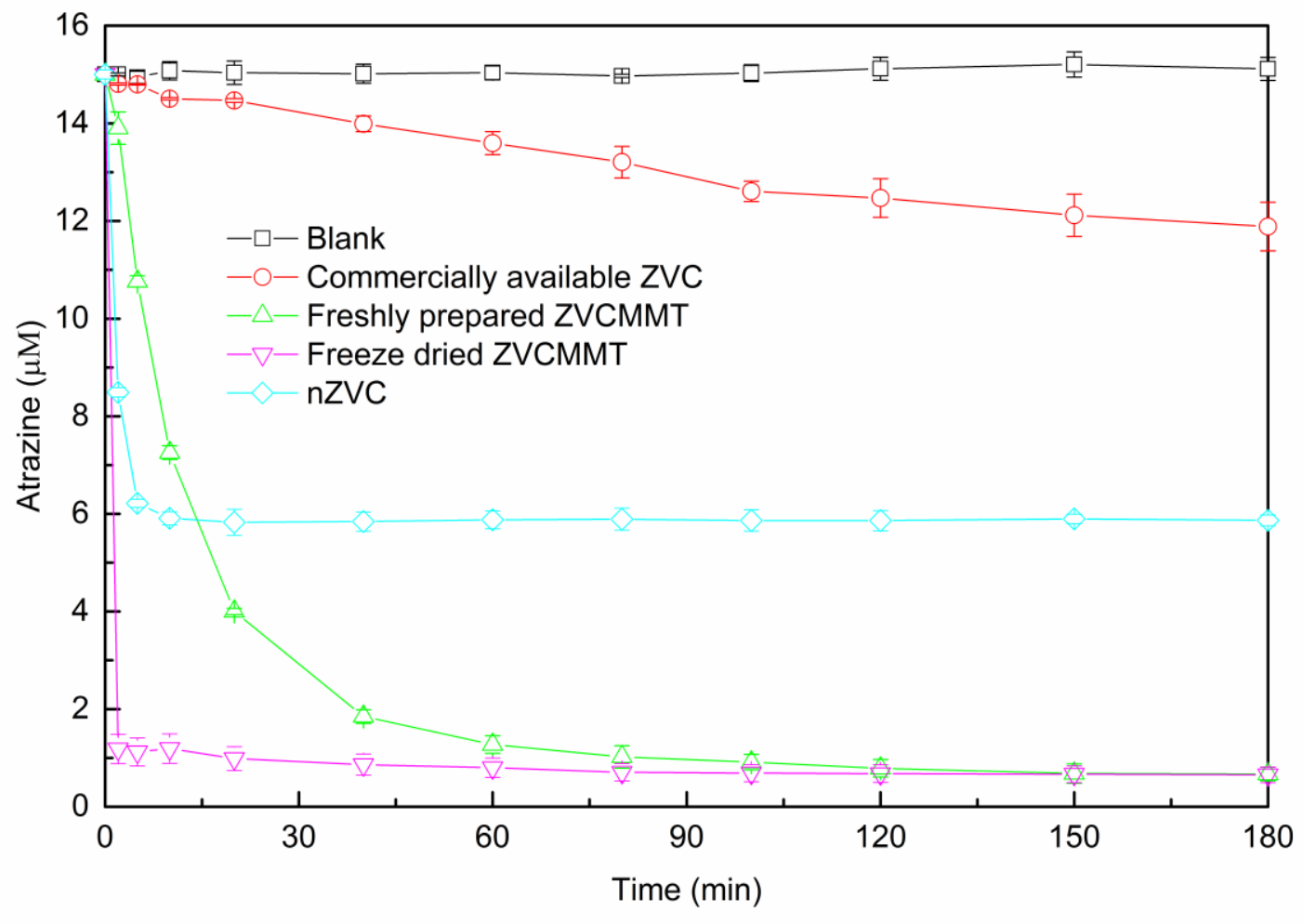

Fig. 4 


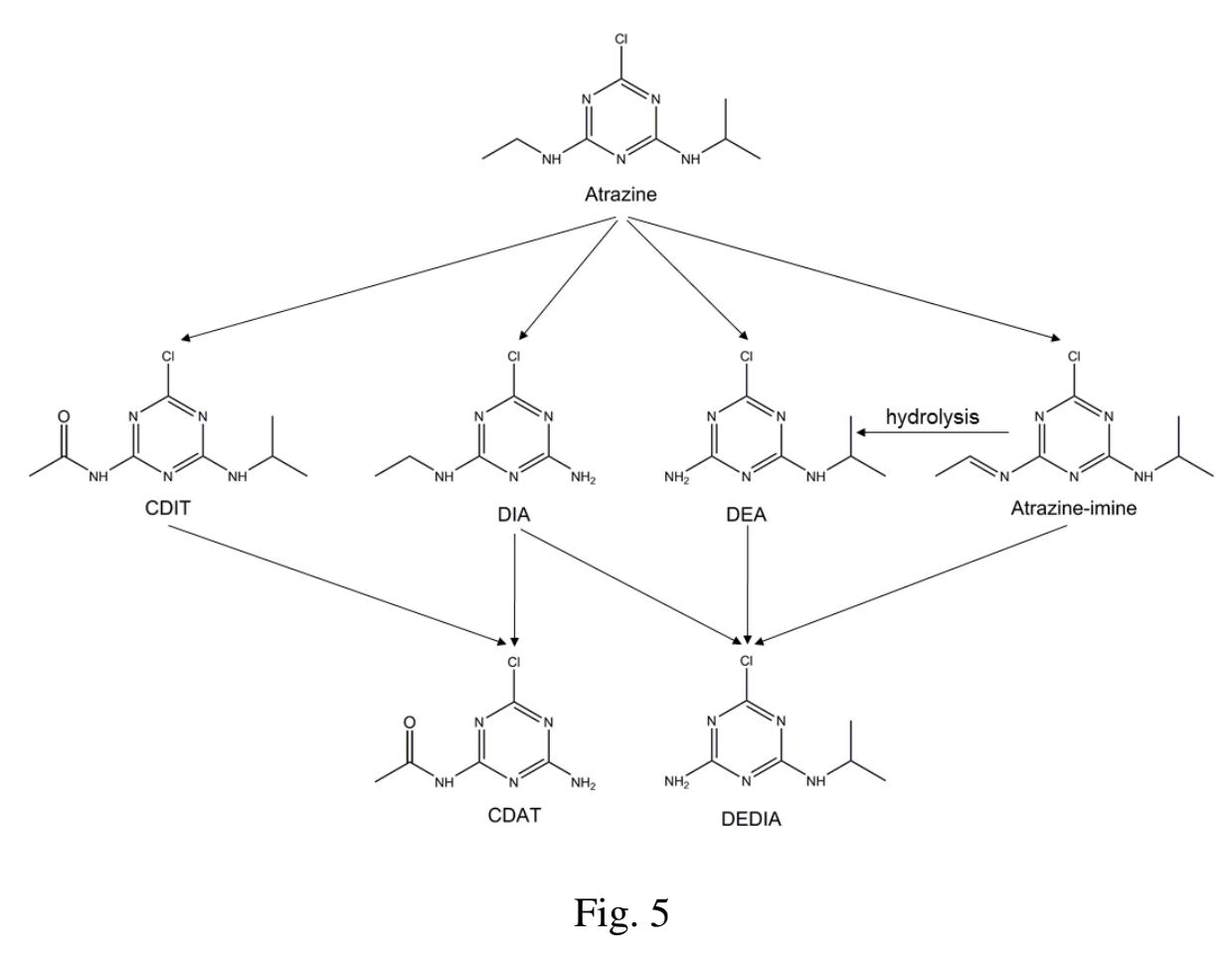




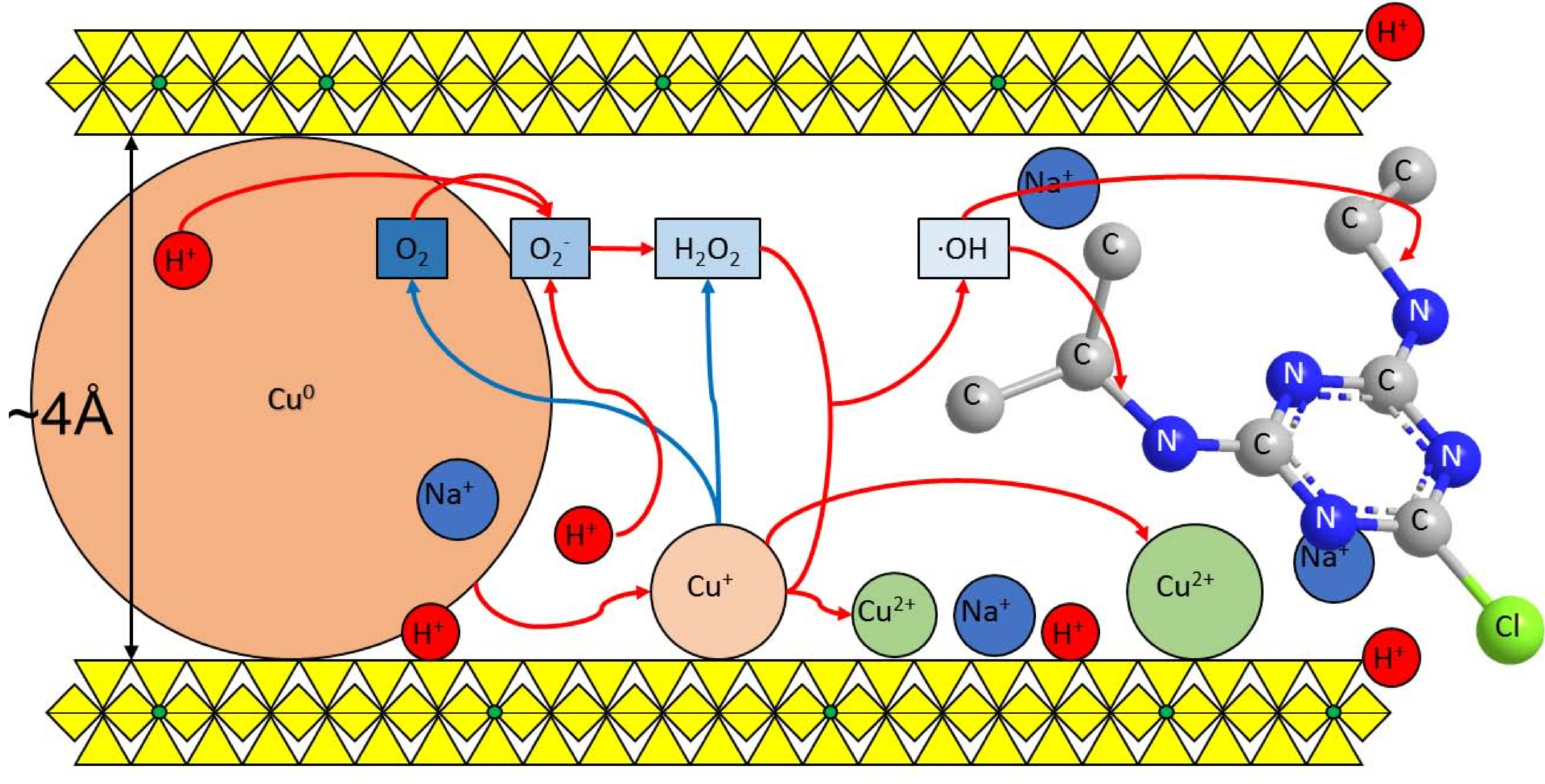

$\triangle$ tetrahedral repeat unit $\diamond$ octahedral repeat unit $\circ$ magnesium atom 